\title{
Effects of d-amphetamine and pilocarpine on the mouse-killing response of hungry and satiated rats
}

\author{
ISRAEL POSNER, WILLIAM M. MILEY, and NICHOLAS J. MAZZAGATTI \\ Stockton State College, Pomona, New Jersey 08239
}

\begin{abstract}
Two experiments examined some relationships between feeding schedule and two psychoactive drugs on the mouse-killing response in rats. Experiment 1 showed that the combination of a high dose of d-amphetamine $(2.00 \mathrm{mg} / \mathrm{kg})$ and food satiation effectively suppresses killing while either factor alone does not. Experiment 2 showed that the combination of a high dose of pilocarpine $(30 \mathrm{mg} / \mathrm{kg})$ and food deprivation induces a considerable percentage of Sprague-Dawley rats to kill mice while either variable alone does not.
\end{abstract}

Leaf, Lerner, and Horovitz (1969) have reported the existence of complex interactions of excitatory and inhibitory controls over mouse-killing by rats. Since drugs of several pharmacological classes can inhibit mouse-killing, it is likely that more than one neurochemical mechanism for inhibition exists. They present some evidence which suggests that the amygdala may mediate these multiple inhibitory controls.

Two antidepressants of different pharmacological classes, Imipramine and Thiazesim, when injected bilaterally into the amygdala, produce immediate inhibition of mouse-killing which lasts 1 to $2 \mathrm{~h}$ without any signs of physical debilitation (Horovitz \& Leaf, 1967). Since injections of these drugs into the nearby centers in the septum or hypothalamus do not inhibit mouse-killing, the effects appear to be localized in the amygdala.

Amphetamines also suppress mouse-killing in rats at doses much lower than those necessary to produce gross debilitation (Horovitz, Piala, High, Burke, \& Leaf, 1966). Horovitz (1965) suggested that a neurochemical action in the amygdala was responsible for the inhibition; this system seems related to the metabolism of the adrenergic transmitter agent, norepinepherine (Leaf, 1970), which is affected by the introduction of amphetamines (Stein, 1964).

One neurochemical system that appears to activate mouse-killing is cholinergic; Leaf et al. (1969) activated mouse-killing in rats which had never killed mice by amygdaloid implantation of the anticholinesterase drug, crystalline eserine. Various cholinomimetic and anticholinesterase drugs have been injected into the hypothalamus, which has close neural connections with the amygdala, resulting in similar

Requests for reprints should be sent to Israel Posner, Psychology Program, Stockton State College, Pomona, New Jersey 08329. effects. For example, Smith, King, and Hoebel (1970) found that intrahypothalamic injections of these classes of drugs caused initiation of mousekilling by rats which had not previously killed mice. McCarthy (1966) also presented evidence that nonkillers, as well as capricious killers, could become well-organized, reliable killers by repeated intraperitoneal injections of pilocarpine (a cholinomimetic drug). That the killing response is drug-dependent was demonstrated by Vogel and Leaf (1972), who found that all rats stopped killing on the first day of pilocarpine withdrawal.

Nondrug manipulations also affect the incidence of mouse-killing. Myer and Baenninger (1966) showed that electric shock contingent upon killing suppressed killing, but that the response recovered within $48 \mathrm{~h}$. Furthermore, food deprivation appears to be of primary importance in facilitating killing (Whalen \& Fehr, 1964), and most rats so induced continue to kill even when subsequently satiated (Paul, Miley, \& Baenninger, 1971). Thus, the maintenance of the killing response induced by pilocarpine requires the presence of the drug, while rats induced to kill by food deprivation continue to kill despite the termination of the potentiating condition, i.e., food deprivation. It therefore appears that pilocarpine and food deprivation do not operate upon the mechanism(s) controlling killing in the same manner.

It has been suggested in the literature that mousekilling by rats typifies predatory aggression (e.g., Moyer, 1968; O'Boyle, 1974), which implies that the variables which affect eating should similarly affect mouse-killing. However, the research evidence bearing on this issue is ambiguous. For example, killing, as well as eating, are activated by food deprivation and also suppressed by amphetamines, thus suggesting overlapping control. However, some researchers have reported evidence which supports 
the notion of a differentiation of eating and killing control (e.g., Berg \& Baenninger, 1974; Paul, 1972). Furthermore, injections of neostigmine (an anticholinesterase) into the hypothalamus activate killing but have no effect on eating (Smith et al., 1970), while food satiation suppresses eating behavior but does not suppress killing induced by deprivation (Paul et al., 1971).

It therefore appears that both feeding schedule and various sympathomimetic and parasympathomimetic drugs can independently affect killing behavior. Little, if anything, has been reported in the literature concerning the relationship between feeding schedule variables and these drugs. Therefore, the following two experiments were conducted to investigate these relationships with the intention of shedding some light on the issue of separateness or overlap of killing and eating mechanisms.

\section{EXPERIMENT 1}

Experiment 1 sought to determine whether eating schedule interacts with d-amphetamine in determining the probability of mouse-killing in a group of rats. It is possible that satiation alone does raise the attack threshold in rats induced to kill by deprivation but not enough to prevent the mouse-killing response. (Informal observations by the authors suggest that killing does stop appreciably with prolonged satiation.) If this is true, then the combined effects of a drug which suppresses mouse-killing, and food satiation, may interact to decrease the probability of mouse-killing more than either variable alone. Since the focus of Experiment 1 was on inhibition of killing, a fairly aggressive strain of rat, the Long-Evans (approximately 15\%-20\% spontaneously kill mice in our lab), was used in this study. Furthermore, since the effects of food deprivation alone on killing are fairly clear (e.g., Paul et al., 1971; Paul \& Posner, 1973), there was little need to run a drug-free control in this study. Instead, we focused on the effect of the drug at two dose levels in food-deprived and satiated subjects.

\section{Method}

Subjects. Thirty-four male, Long-Evans rats, weighing 200-250 g, were obtained from Huntington Farms, West Conshohocken, Pennsylvania, and served as subjects in Experiment 1 .

Procedure. After arrival at the lab, the rats were given three days of adaptation to their individual wire-mesh cages with free access to Purina Lab Chow and water. Prior to the actual experimental procedures, the rats underwent a series of pretests to obtain a pool of reliable killers which would kill under deprived and satiated conditions. The preexperimental phase began on Days 4 and 5, at which time the rats were completely deprived of food; from Day 6 to Day 18, they were maintained on a 23-h cyclic food-deprivation schedule. On Days 16,17, and 18, all rats were tested for killing. In each of the daily tests, a live adult albino mouse was dropped into the subject's cage. If a kill occurred, the carcass was removed within $15 \mathrm{sec}$; if not, the live mouse was removed after $30 \mathrm{~min}$. All tests were given $1 \mathrm{~h}$ prior to the regularly scheduled feeding time. Following the tests on Day 18, all rats were given free access to food until Day 23. On Days 22 and 23, they were again tested for mouse-killing; two animals which did not kill on these days were discarded. Thus, all rats that served as subjects were highly reliable killers. The experimental procedures began on Day 24 , at which time the subjects were randomly assigned to one of four groups. From Day 24 to Day 27, two groups of rats were placed on 23-h food deprivation (D groups) and two other groups were allowed free access to food (S groups). D-amphetamine was administered subcutaneously on Day $271 \mathrm{~h}$ after the start of the dim phase of a reverse light-dim cycle in the following amounts: Groups LD (low dose, deprived) and LS (low dose, satiated) received $.50 \mathrm{mg} / \mathrm{kg}$ and Groups HD (high dose, deprived) and HS (high dose, satiated) received $2.00 \mathrm{mg} / \mathrm{kg}$. All groups were tested for mouse-killing $1 \mathrm{~h}$ after the drug was administered. The tests were given $11 / 2 \mathrm{~h}$ prior to the regularly scheduled feeding time.

\section{Results}

Figure 1 shows the effects of d-amphetamine and feeding schedule on mouse-killing. A binomial test

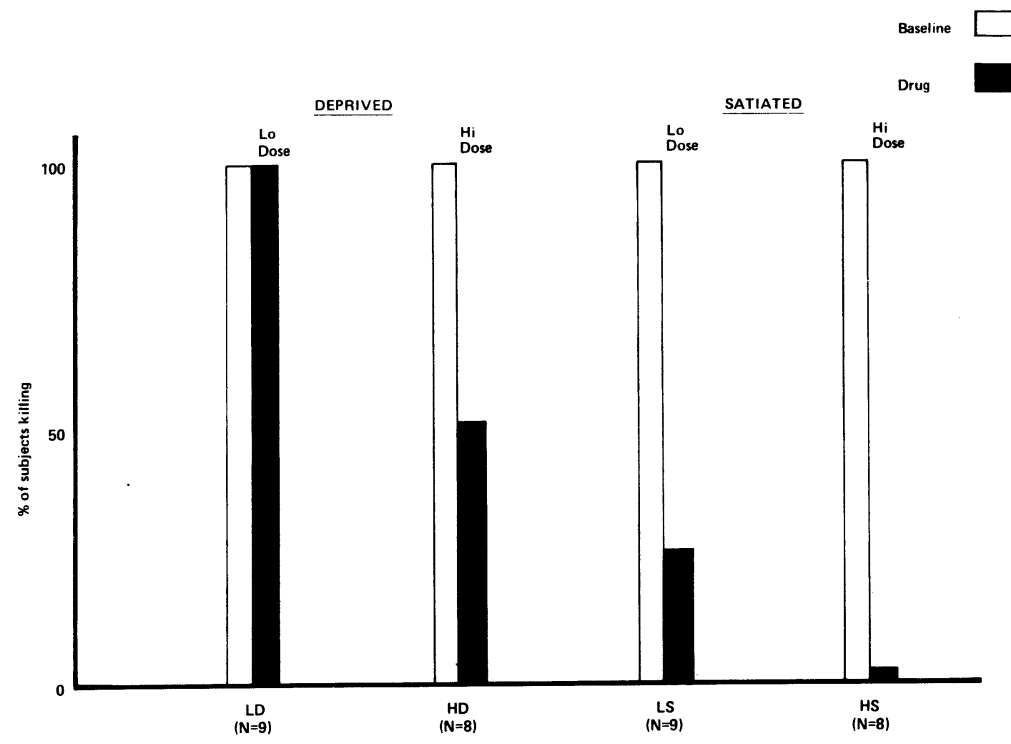

Figure 1. Effects of d-amphetamine and feeding schedule on mouse killing by rats. 
comparing the number of subjects in Groups LS and HS which killed mice prior to the experimental procedures $(9 / 9$ and $8 / 8$, respectively, or $17 / 17=$ $100 \%$ ) and the number of subjects which killed after $(2 / 9$ and $0 / 8$, respectively, or $2 / 17=12 \%)$ showed that $\mathrm{d}$-amphetamine significantly reduced killing $(p<.002)$ under conditions of food satiation. In contrast, under deprivation in Groups LD and HD, the d-amphetamine did not reduce killing $(p>.05)$. The overall significant reduction in killing in the satiated groups was mostly attributed to Group HS (none killed after treatment), which received the high drug dosage $(p<.01)$. While the reduction in killing was not significant in Group LS, which received the low dosage ( $p>.05$ ), $77 \%$ ( 7 out of 9 ) of these subjects did not kill after treatment.

\section{EXPERIMENT 2}

Thus, Experiment 1 showed that d-amphetamine does not suppress killing in killers which are food deprived but clearly does suppress killing in food satiated killers at high doses. Furthermore, although satiation alone does not normally inhibit killing in rats which have been induced to kill by food deprivation (Paul et al., 1971), Experiment 1 showed that the combined effects of food satiation and damphetamine do completely suppress mouse-killing even in highly reliable and experienced killers. These data are consistent with previous studies which demonstrate the antagonistic action of food deprivation and amphetamine on killings in different groups of subjects. The current findings extend this relationship and demonstrate this antagonistic effect even within the same subjects. The data presented here also show a trend toward a dose-response relationship such that high doses of amphetamine may suppress even deprived killers.

While Experiment 1 examined the relationship between the feeding schedule variable and the suppressive effects of d-amphetamine, Experiment 2 was conducted to examine how the activating effect of pilocarpine is affected by feeding schedule. In order to prevent a "ceiling" effect with respect to killing, a fairly docile strain of rat, the Sprague-Dawley (approximately 2\% kill spontaneously in our lab), was used in this study. In Spargue-Dawleys, which have a low rate of spontaneous killing, food deprivation produces relatively small increases in the probability of killing (Paul et al., 1971). However, perhaps even in Sprague-Dawleys, food deprivation does move the killing response closer to threshold, but not sufficiently to reach killing threshold. Therefore, Experiment 2 sought to determine whether the combined effects of pilocarpine and deprivation are more potent than either factor alone in the activation of killing in a docile stain.

\section{Method}

Subjects. Thirty-nine adult male Sprague-Dawley rats, weighing between 200 and $250 \mathrm{~g}$, were obtained from Huntington Farms and housed in individual wire-mesh cages.

Procedure. Adaptation to cages and preexperimental testing was identical to Experiment 1 . Then subjects were randomly assigned to one of four groups. On Days 4 to 11 , two groups were maintained on 23-h cyclic food deprivation (D groups) while the two remaining groups remained on an ad-lib feeding schedule (S groups).

During Days 4 to 11 , one of the two deprived groups (PD) and one of the two satiated groups (PS) received, once daily, intraperitoneal injections of $30 \mathrm{mg} / \mathrm{kg}$ pilocarpine at the same time as in Experiment 1. The other deprived and satiated groups received once daily injections of physiological saline. Thus a 2 by 2 design was employed; subjects were either deprived or satiated and received either pilocarpine or saline injections.

On Day 11, all subjects were tested for mouse-killing as described in Experiment 1. Furthermore, as in Experiment 1, all tests took place $1 \frac{1}{2} \mathrm{~h}$ prior to the regularly scheduled feeding time.

\section{Results}

Table 1 shows the number of animals which killed mice in each of the four groups. Comparison of the pilocarpine groups (Groups PD and PS) with the saline groups (Groups SD and SS) showed that the pilocarpine groups killed significantly more mice $\left(8 / 20\right.$ vs $\left.1 / 19, x^{2}=4.81, \mathrm{df}=1, \mathrm{p}<.05\right)$ than did the saline groups. Comparison of the pilocarpinedeprived group (Group PD) with the saline-satiated group (Group SS) showed that Group PD killed more mice $(6 / 10=60 \%)$ than did Group SS $\left(0 / 10=0 \%, x^{2}=5.95, \mathrm{df}=1, \mathrm{p}<.02\right)$. A comparison between the pilocarpine-deprived group (Group PD) and the saline-deprived group (SD) showed no significant differences, although they approached significance very closely $\left(x^{2}=2.99\right.$, $\mathrm{df}=1, \mathrm{p}<.10)$. The two pilocarpine groups (PD and PS) did not differ $(p>.10)$ in rate of killing. Thus, deprivation alone does not induce killing in Sprague-Dawleys, but pilocarpine plus deprivation clearly does.

\section{DISCUSSION}

Experiment 1 showed that the combination of food satiation and d-amphetamine suppresses mouse-killing in a strain of rat with a fairly high rate of spontaneous mouse-killing, while food satiation alone does not (Paul et al., 1971). Furthermore, d-amphetamine did not completely suppress the

Table 1

The Effects of Pilocarpine and Feeding Schedule on Mouse Killing by Rats

\begin{tabular}{lcll}
\hline \multicolumn{1}{c}{ Group } & Subjects & \multicolumn{2}{l}{$\begin{array}{l}\text { N of Subjects } \\
\text { which Killed }\end{array}$} \\
\hline Pilocarpine Deprived & 10 & 6 & $(60 \%)$ \\
Pilocarpine Satiated & 10 & 2 & $(20 \%)$ \\
Saline Deprived & 9 & 1 & $(11.1 \%)$ \\
Saline Satiated & 10 & 0 & $(0 \%)$ \\
\hline
\end{tabular}


response in deprived subjects. Experiment 2 showed that food deprivation and pilocarpine induced mouse-killing in Sprague-Dawley rats which were not induced by food deprivation or pilocarpine alone. Thus, food satiation alone and a low d-amphetamine dose alone were not sufficient to completely suppress mouse killing (Experiment 1), nor was cyclic food deprivation alone or pilocarpine alone sufficient to induce mouse-killing (Experiment 2) in Sprague-Dawleys.

The results of these experiments suggest that there are complex relationships between feeding regimen and the effects of psychoactive drugs on killing. Clearly, the state of food deprivation interfered with the suppressive effects of d-amphetamine. Furthermore, pilocarpine is a more effective excitatory agent in deprived rats than in satiated ones. It appears, therefore, that the feeding variable does modulate the control of killing by psychoactive drugs and suggests that killing and eating mechanisms are indeed intricately related in the rat's brain.

\section{REFERENCES}

Berg, D., \& BaEnNinger, R. Predation: Separation of aggressive and hunger motivation by conditioned aversion. Journal of Comparative and Physiological Psychology, 1974, 86, 601-606.

Horovitz, Z. P. Psychoactive drugs and limbic system of the brain. Psychosomatics, 1965, 6, 281-286.

Horovitz, Z. P., \& LEAF, R. C. The effects of direct injections of psychotropic drugs on the amygdalae of rats and the relationship to antidepressant site of action. In H. Brill, J. O. Cole, P. Deniker, H. Hippuis, \& P. B. Bradley (Eds.), Excerpta Medica International Congress Series No. 129. Amsterdam: Excerpta Medica Foundation, 1967.

Horovitz, Z. P., Piala, J. J., High, J. P., Burke, J. C., \& Leaf, R. C. Effects of drugs on the mouse-killing (muricide) test and its relationship to amygdaloid function. International Journal of Neuropharmacology, 1966, 5, 405-411.
LEAF, R. C. Pharmacology, limbic regulation and cortical function. In W. L. Smith (Ed.), Drugs and cerebral function. Springfield: Thomas, 1970.

Leaf, R. C., Lerner, L., \& Horovitz, Z. P. The role of the amygdala in the pharmacological and endocrinological manipulation of aggression. In S. Garattini \& E. B. Sigg (Eds.), Aggressive behaviour. Amsterdam: Excerpta Medica Foundation, 1969.

MCCARTHY, D. Mouse-killing induced in rats treated with pilocarpine. Federation Proceedings, 1966, 25, 385. (Abstract)

MOYER, K. E. Kinds of aggression and their physiological basis. Communications in Behavioral Biology, 1968, 2, 65-87.

Myer, J. S., \& Baenninger, R. Some effects of punishment and stress on mouse-killing by rats. Journal of Comparative and Physiological Psychology, 1966, 62, 292-297.

O'Boyle, M. Rats and mice together: The predatory nature of the rat's mouse-killing response. Psychological Bulletin, 1974, 4, 261-269.

Paul, L. Predatory attack by rats: Its relationship to feeding and type of prey. Journal of Comparative and Physiological Psychology, 1972, 78, 69-76.

Paul, L., Miley, W. M., \& Baenninger, R. Mouse-killing by rats: Roles of hunger and thirst in its initiation and maintenance. Journal of Comparative and Physiological Psychology, 1971, 76, 242-249.

Paul, L., \& Posner, I. Predation and feeding: Comparisons of feeding behavior of killer and non-killer rats. Journal of Comparative and Physiological Psychology, 1973, 84, 258-264.

Smith, D. E., King, M. B., \& Hoebel, B. G. Lateral hypothalamic control of killing: Evidence for a cholinoceptive mechanism. Science, 1970, 167, 900-901.

Stein, L. Amphetamine and neural reward mechanisms. In $\mathrm{H}$. Steinberg, A. V. S. de Reuck, \& J. Knight (Eds.), Ciba Foundation symposium on animal behavior and drug action. London: Churchill, 1964.

Vogel, J. R., \& Leaf, R. C. Initiation of mouse killing in nonkiller rats by repeated pilocarpine treatment. Physiology and Behavior, 1972, 8, 421-424.

WhALEN, R. E., \& FEHR, H. The development of the mouse-killing response in rats. Psychonomic Science, 1964, 1, 77-78.

(Received for publication April 16, 1976; revision accepted August 20, 1976.) 